\title{
A Luminescent Metal-Organic Framework for Sensing Methanol in Ethanol Solution
}

\author{
Zhao Jin, ${ }^{a}$ Hongming He, ${ }^{a}$ Huanyu Zhao, ${ }^{b}$ Tsolmon, Borjigin, ${ }^{a}$ Fuxing Sun, ${ }^{a}$ Daming Zhang ${ }^{c}$ and Guangshan Zhu ${ }^{* a b}$
}

\author{
${ }_{5}$ Received (in $\left.X X X, X X X\right) X$ th $X X X X X X X X X 20 X X$, Accepted $X$ th $X X X X X X X X X 20 X X$ \\ DOI: 10.1039/b000000x
}

A new luminescent Zn-MOF has been synthesized under hydrothermal condition using a semi-rigid ligand $\mathrm{H}_{3}$ pcoip (4(2-carboxyphenoxy)isophthalic acid). The luminescence ${ }_{10}$ properties of $\mathbf{1}$ in methanol, ethanol, and water have been investigated respectively. Interestingly, compound 1 have a unique response to methanol molecule against ethanol and water. Moreover, 1 performs a turn-on switching property trigged by methanol solvent molecule and a high sensitivity

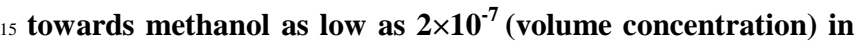
ethanol solution. The results indicate that the Zn-MOF has potential application as a sensor for detecting methanol in ethanol solution with excellent selectivity and highly sensitivity.

20 In the last two decades, porous metal-organic frameworks (MOFs) materials which constructed from metal ions/metal clusters as nodes and multitopic organic ligands as linkers have drawn widespread attention not only because of their intriguing varieties of architectures and topologies ${ }^{1-6}$ but also owing to a wide range 25 of their potential applications in selective adsorption/separation, ${ }^{7-}$ ${ }^{9}$ heterogeneous catalysis ${ }^{10-13}$ and light-emission diode (LED) ${ }^{14-17}$ etc.. Among a plethora of porous frameworks investigated, a large number of luminescent MOFs have been reported in the literature. However, only a few of them, which have specific and so detective change in luminescence when contacting an analyte, have potential application in chemical sensor.

Generally, luminescent MOFs are classified as transition-metal MOFs and lanthanide-MOFs (Ln-MOFs) according to the type of metal used. In Ln-MOFs system, intensity change of lanthanide

35 luminescent signal caused by analyte-metal or analyte-ligand interaction occurs. ${ }^{18-20}$ By contrast, many luminescent transitionmetal MOFs exhibit turn-on switching property triggered by analytes. $^{21-26}$ Position of their responsive emission usually changes upon those interactions. Compared to common 40 luminescence-enhancing/quenching method, detection occurs relative to a dark background is intrinsically more sensitive.

As a very important raw material, ethanol is widely used in many field like chemical industry, food industry etc. Methanol, a cheaper and more easily accessible analogue of ethanol,
45 sometimes is mixed into ethanol to reduce the cost of ethanol producing, and sometimes it is even used in producing imitated spirits and wine. But, methanol is an alcohol toxic to mammals, overtake of the compound will cause headache, vomiting, blindness or even worse. That leads one of the highest risks to 50 food safety worldwide. Therefore detection of methanol in ethanol and alcoholic beverages is of great significance and necessity. Actually, it's hard to differentiate methanol and ethanol because of their similar chemical and physical properties. Generally, high performance liquid chromatography ${ }^{27}$, gas 55 chromatography $^{28}$, and Raman spectroscopy ${ }^{29}$ etc. are usually used for detecting methanol. But their high cost, inconvenience and inefficiency impede their wild application in daily life. Herein, we report a novel luminescent transition-metal MOF exhibiting efficient turn-on switching property triggered by 60 solvent molecule, with fast response, excellent selectivity and highly sensitivity for methanol molecule. To the best of our knowledge, this is the first report of luminescent-MOF based sensor displaying such capability.

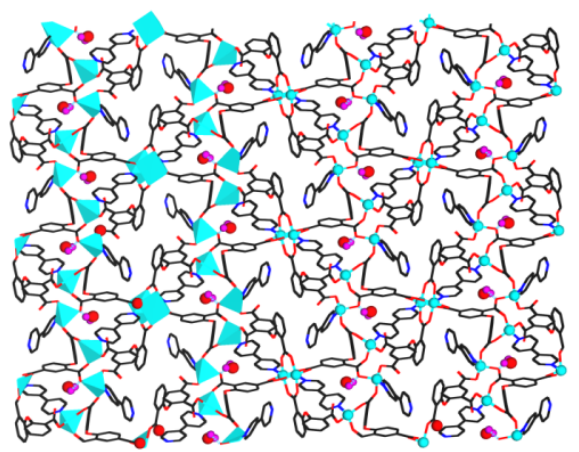

${ }_{65}$ Fig. 1 Perspective view of the 3D framework with the guest water in the channel along a-axis. Colour code: Zn, Cyan; C, Black; N, Blue; O, Red; H, Magenta.

Colorless crystals of $\left[\mathrm{Zn}_{3}(\text { cpoip })_{2}\left(4,4^{\prime}-\text {-bpy }\right)_{2} \cdot \mathrm{H}_{2} \mathrm{O}\right](\mathbf{1})\left(4,4^{\prime}\right.$-bpy $=$ $4,4^{\prime}$-bipyridine) has been synthesized by heating a solution of $70 \mathrm{Zn}\left(\mathrm{NO}_{3}\right)_{2} \cdot 6 \mathrm{H}_{2} \mathrm{O}$ (0.03 g), 4,4'-bpy (0.016 g ), $\mathrm{H}_{3}$ cpoip (0.03 g), $\mathrm{NaOH}(0.01 \mathrm{~g})$ and $\mathrm{H}_{2} \mathrm{O}(7 \mathrm{~mL})$ at $130^{\circ} \mathrm{C}$. The crystal structure of $\mathbf{1}$ is shown in Fig. 1 and S2. Two adjacent Zn1 atoms linked by four carboxylate groups from four ligands give a binuclear paddle-wheel unit (Fig. S2a). The modes of metal-ligand 
connectivity at Zn2 and Zn3 are quite similar and both of them contain tetrahedral $\mathrm{Zn}$ centers of which the apical are occupied by one nitrogen atom and three oxygen atoms which from three different carboxylate groups (Fig S2b, c). The bond lengths of ${ }_{5} \mathrm{Zn}-\mathrm{O}[1.921(2)$ - 2.048(2) $\AA]$ and Zn-N [2.027(2) - 2.043(2) $\AA$ ] are all within the normal range ${ }^{30}$. Meanwhile, two types of cpoip $^{3-}$ ligands denoted as L1 and L2 are also found in 1. All the three carboxylate groups of L1 exhibit a bis-monodentate coordination mode, and two $\mathrm{O}$ atoms from two different carboxylate groups 10 bind to $\mathrm{Zn}(2)$ via chelate fashion. Therefore, L1 displays $u_{5^{-}} \eta^{1}$ : $\eta^{1}: \eta^{1}: \eta^{1}: \eta^{1}: \eta^{1}$ coordination mode to link five adjacent $\mathrm{Zn}$ atoms. Carboxylate groups from isophthalate moiety of L2 adopt monodentate mode to link to two $\mathrm{Zn}$ atoms, and the other one ligates to two Zn atoms via bis-monodentate mode (Fig.S3). 4,4'15 bpy ligands here also adopt two coordination manner, one connects Zn1 paddle-wheel unit and Zn2 acting as a linker, and the other one binds $\mathrm{Zn} 3$ as a terminal molecular. On the basis of the coordination mode of $\mathrm{L} 1$ and conformation of ligand cpoip $^{3-}$, the adjacent Zn2 and Zn3 atoms are connected into a 1D zigzag 20 chain along crystallographic $b$-axis (Fig. S2d). This 1D chain further interconnect with each other via isophthalate moiety of L2 along $a$-axis giving 2D layers as depicted in (Fig. S2e). Finally, the adjacent 2D layers are connected by Zn1 binuclear paddlewheel unit and the bidentate $4,4^{\prime}$-bpy along $c$-axis to generate a 25 3D framework. The guest water molecules are found in the channel along $a$-axis which surrounded by L1, bidentate 4,4'-bpy and $\mathrm{Zn}$ atoms (Fig. 1). Intermolecular $\mathrm{H}-\mathrm{O} \cdots \mathrm{H}$ hydrogen bonding interaction between guest water molecules and a carboxyl oxygen atoms $(\mathrm{O} 3)(\mathrm{d}(\mathrm{O} 15 \cdots \mathrm{O} 3)=2.919 \AA$ and $\angle \mathrm{O} 15-\mathrm{H} 151 \cdots \mathrm{O} 3=$ $30126.19^{\circ}$ ) is also found ${ }^{31,32}$. Although there is a $1 \mathrm{D}$ channel in the framework, gas adsorption data can't be obtained. Because the framework collapses once the guest water molecules removed. This phenomenon indicates that the guest water molecular plays a key role in stabilizing the pore structure.

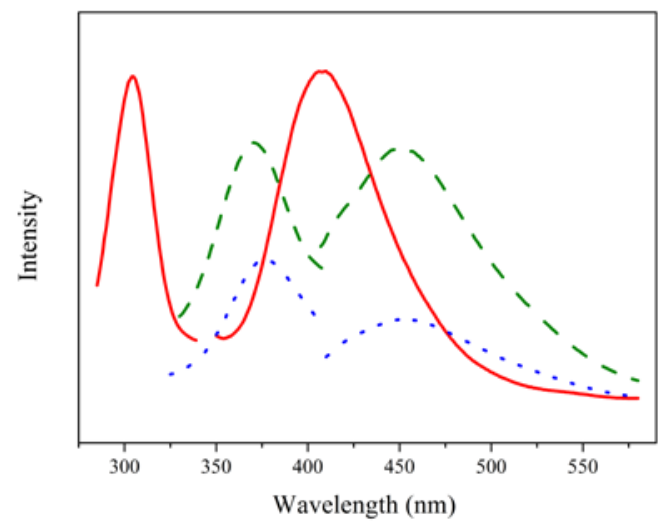

Fig. 2 Luminescence spectra of 1 in methanol (red solid); water (green dash); ethanol (blue dot).

Differential scanning calorimetry (DSC) (Fig. S4) curve presents an endothermal peak between 70 and $140{ }^{\circ} \mathrm{C}$, meanwhile the 40 thermogravimetric analysis (TGA) curve shows $1.8 \%$ weight loss (calculated: $1.6 \%$ ) in this temperature range, which reveals release of the guest water molecules. An abrupt weight loss in TGA curve and two obvious exothermic peaks in DSC curve were observed in the range of 370 and $480{ }^{\circ} \mathrm{C}$, indicating collapse 45 of the whole framework. Powder XRD patterns were used to examine the structural homogeneity of bulk powder samples of $\mathbf{1}$. The peak positions of experimental patterns match well with those of simulated ones from single-crystal X-ray diffraction data (Fig. S5), which indicates the homogeneous phase of final 50 products of $\mathbf{1}$.

To investigate the luminescence properties of $\mathbf{1}$, the luminescence spectrum of $\mathbf{1}$ in solid state has been firstly studied. The complex displays a blue emission band with an intense peak maximum at $448 \mathrm{~nm}$ upon excitation at $377 \mathrm{~nm}$, (Fig. S7). According to the 55 previous reports, the emission of $\mathbf{1}$ can be attributed to the $\mathrm{Zn}-\mathrm{O}$ inorganic cluster which closely resembles $\mathrm{ZnO}$ oxide nanostructure in MOF structure. ${ }^{33,34}$ It's also found that the emission of $\mathrm{Zn}-\mathrm{O}$ inorganic cluster in MOF can be strongly influenced by guest molecules. ${ }^{35}$ Encouraged by the result above, 60 the luminescence response behavior of $\mathbf{1}$ in methanol, ethanol and water emulsion was further investigated, respectively. As shown in Fig 2, 1 exhibits different luminescent properties when dispersed in different solvent. When exited at $377 \mathrm{~nm}, \mathbf{1}$ in ethanol and water emulsion displays the similar emission spectra 65 with that of $\mathbf{1}$ in solid state. But in methanol, no responsive emission is observed. Instead, an obvious blue-shift emission at $404 \mathrm{~nm}$ is observed upon excitation at $304 \mathrm{~nm}$. These results indicate that $\mathbf{1}$ may have a unique response to methanol molecule against ethanol and water. Considering the pore size along the $\mathrm{H}$ 70 bond direction (4.60 $\AA$ ) is bigger than the size of water and methanol molecules, 2.55 and $3.84 \AA$, respectively, but smaller than that of ethanol (5.07 $\AA$ ), we speculate the selectivity of methanol and ethanol for 1 is mainly dependence on the size effect of the pore and the analytes. (Fig S8)

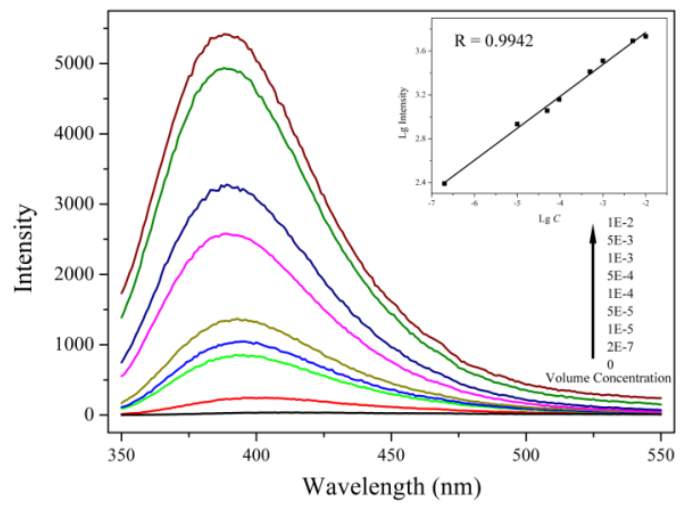

Fig. 3 Emissive response spectra of $\mathbf{1}$ for methanol in ethanol solution with different methanol volume concentration. Plot of $L g$ value of luminescence intensity (Y) versus the $L g$ value of methanol volume concentration (inset).

80 Inspired by such solvent dependent luminescent properties, more detail studies were carried out in methanol/ethanol binary system. 1 was dispersed in ethanol as the standard emulsion, while the methanol solvent was gradually increased to monitor the emissive response. As shown in Figure 3, the standard emulsion without 85 methanol shows no detectable luminescent response signal when exited at $304 \mathrm{~nm}$. With increasing methanol concentration, the 
luminescence intensity of $\mathbf{1}$ emulsion gradually increased. This turn-on switching property trigged by methanol solvent molecule and excellent selectivity make $\mathbf{1}$ a potential candidate for sensing methanol from ethanol. It's noteworthy that the luminescence 5 intensity is strong enough to be detected even when the methanol concentration is as low as $2 \times 10^{-7}$ (volume concentration). It indicates that $\mathbf{1}$ has highly sensitivity to be qualified to trace amount detection of methanol. In addition, 1 still remains its crystal structure after sensing tests. (Fig S5)

10 The relationship of the increasing trend of luminescence intensity versus the volume ratio of methanol was further studied. The results revealed that there was a good linear relationship $\left(\mathrm{R}^{2}>\right.$ 0.99) between $L g I$ and $L g C\left(L g I=\log _{10} I, I=\right.$ luminescence intensity of 1 emulsion with different methanol concentration, $C$ 15 = methanol volume concentration). That means that the methanol content in ethanol solution could be quantified in the linear range of 0 to 0.01 . The equation calculated is $Y=0.2914 X+4.35134$.

The similar emission behavior of $\mathbf{1}$ was also found in methanol/ $\mathrm{H}_{2} \mathrm{O}$ binary system. (Fig S9) The higher detection limit 20 of methanol concentration $\left(1 \times 10^{-4}\right)$ is mainly due to competitive adsorption between water and methanol molecules. According to the results above, detection of methanol using $\mathbf{1}$ in imitated alcoholic beverage $\left(V_{\text {methanol }} / V_{\text {ethanol }} / V_{\text {water }}=0.05 / 250 / 250\right)$ was further carried out. The result confirms that $\mathbf{1}$ has unique response 25 to methanol molecule in presence of ethanol and water, indicting $\mathbf{1}$ can be used as a sensor to detect trace amount methanol in alcoholic beverage.

In summary, a novel 3D Zn-MOF (1) based on semi-rigid ligand $\mathrm{H}_{3}$ cpoip has been successfully synthesized under hydrothermal 30 condition. The luminescence properties of $\mathbf{1}$ in different solvent have been investigated. Experimental results indicate that $\mathbf{1}$ perform a turn-on switching property trigged by methanol solvent molecule and a high sensitivity towards methanol as low as $2 \times 10^{-}$ ${ }^{7}$ (volume concentration) in ethanol solution. Furthermore, the 35 concentration of methanol in the methanol/ethanol mixture can be quantified according to the fluorescence intensity in the range of 0-0.01. Compound $\mathbf{1}$ was also proved to be an excellent candidate sensor for detecting trace amount methanol in alcoholic beverages. It is the first report about MOF-based sensor in such 40 application area. And we believe it could play an essential role on food safety in the future.

\section{Acknowledgments}

We gratefully acknowledge the financial support from Australia Research Council (ARC) through the ARC Future Fellowships 45 program (No. FT100100344).

\section{Notes and references}

${ }^{a}$ State Key Laboratory of Inorganic Synthesis \& Preparative Chemistry, Jilin University, Changchun 130012 (China) Fax: (+86) 431-8516-8331

${ }^{b}$ Queensland Micro- and Nanotechnology Centre, Griffith University, 50 Nathan QLD 4111 Australia, g.zhu@griffith.edu.au

${ }^{c}$ College of electronic science \& engineering, Jilin University, Changchun 130012 (China) (+86) 0431-85168097(0)
† Electronic Supplementary Information (ESI) available: Details of experimental results, ORTEP drawing, TGA-DSC, PXRD patterns, 55 luminescence spectrum, CCDC-891964. For ESI and crystallographic data in CIF See DOI: 10.1039/b000000x/

‡ Crystal data: $\mathrm{C}_{50} \mathrm{H}_{28} \mathrm{~N}_{4} \mathrm{O}_{15} \mathrm{Zn}_{3}, \quad M=1120.87$, colorless block, monoclinic, space group $P 21 / \mathrm{c}$ (No. 14), a $=10.235(2) \AA, \mathrm{b}=14.898(3)$ $\AA, \mathrm{c}=30.275(6) \AA, \beta=101.897(6)^{\circ}, \mathrm{V}=4517.2(16) \AA^{3}, \mathrm{Z}=4, \rho_{\text {calcd }}=$ $601.648 \mathrm{~g} \mathrm{~cm}^{-3}, \lambda_{\text {(Mo-Ka) }}=0.71073 \AA, \theta_{\max }=20.51$, Total data $=28285$, Unique data $=10948,\left(\mathrm{R}_{\text {int }}=0.0566\right)$, Completeness $=96.3 \%, \mathrm{R}_{1}=$ $0.0564, w \mathrm{R}_{2}=0.1398,(\mathrm{I}>2 \sigma), G O F=1.027$. crystallographic data for this paper and the selected bond lengths and angles were displayed in Table. S1 and Table. S2.

65

1.G. Fe'rey, C. Mellot-Draznieks, C. Serre, F. Millange, J. Dutour, S. Surble and I.Margiolaki, Science, 2005, 309, 2040-2042.

2.Q. Fang, G. Zhu, X. Shi, G. Wu, G. Tian, R. Wang and S. Qiu, J Solid 70 State Chem, 2004, 177, 1060-1066.

3.K. S. Park, Z. Ni, A. P. Cote, J. Y. Choi, R. Huang, F. J. Uribe-Romo, H. K. Chae, M. O'Keeffe and O. M. Yaghi, PNAS, 2006, 103, 1018610191.

4.Q. Fang, X. Shi, G. Wu, G. Tian, G. Zhu, R. Wang and S. Qiu, J Solid 75 State Chem, 2003, 176, 1-4.

5.M. Xue, G. Zhu, Y. Zhang, Q. Fang, I. J. Hewitt and S. Qiu, Cryst Growth Des, 2008, 8, 427-434.

6.Q. Fang, G. Zhu, M. Xue, J. Sun, Y. Wei, S. Qiu and R. Xu, Angew

Chem Int Ed, 2005, 44, 3845-3848.

80 7.B. Li, Z. Zhang, Y. Li, K. Yao, Y. Zhu, Z. Deng, F. Yang, X. Zhou, G. Li, H. Wu, N. Nijem, Y. J. Chabal, Z. Lai, Y. Han, Z. Shi, S. Feng and J. Li, Angew Chem Int Ed 2012, 51, 1412-1415.

8.J. R. Li, J. Sculley and H. C. Zhou, Chem Rev, 2012, 112, 869-932. 9.Z. Jin, H. Y. Zhao, X. J. Zhao, Q. R. Fang, J. R. Long and G. S. Zhu, 85 Chem Commun, 2010, 46, 8612-8614.

10.A. Corma, H. Garc1'a and F. X. L. s. i. Xamena, Chem. Rev. , 2010, 110, 4606-4655.

11.A. Dhakshinamoorthy and H. Garcia, Chem Soc Rev, 2012, 41, 52625284.

90 12.Y. K. Hwang, D. Y. Hong, J. S. Chang, S. H. Jhung, Y. K. Seo, J. Kim, A. Vimont, M. Daturi, C. Serre and G. Ferey, Angew Chem Int Ed, 2008, 47, 4144-4148.

13.B. Yuan, Y. Pan, Y. Li, B. Yin and H. Jiang, Angew Chem Int Ed, 2010, 49, 4054-4058.

95 14.J. He, M. Zeller, A. D. Hunter and Z. Xu, J Am Chem Soc, 2012, 134, 1553-1559.

15.Y. Liu, M. Pan, Q.-Y. Yang, L. Fu, K. Li, S.-C. Wei and C.-Y. Su, Chem Mater, 2012, 24, 1954-1960.

16.T. E. Rosson, S. M. Claiborne, J. R. McBride, B. S. Stratton and S. J. 100 Rosenthal, J Am Chem Soc, 2012, 134, 8006-8009.

17.M.-S. Wang, S.-P. Guo, Y. Li, L.-Z. Cai, J.-P. Zou, G. Xu, W.-W. Zhou, F.-K. Zheng and G.-C. Guo, J Am Chem Soc, 2009, 131, 1357213573.

18.B. Chen, L. Wang, F. Zapata, G. Qian and E. B. Lobkovsky, J Am 105 Chem Soc, 2008, 130, 6718-6719.

19.Y. Li, S. Zhang and D. Song, Angew Chem Int Ed, 2013, 52, 710-713. 20.B. Zhao, X.-Y. Chen, P. Cheng, D.-Z. Liao, S.-P. Yan and Z.-H. Jiang, J Am Chem Soc, 2004, 126, 15394-15395.

21.A. Lan, K. Li, H. Wu, D. H. Olson, T. J. Emge, W. Ki, M. Hong and J. 110 Li, Angew Chem Int Ed, 2009, 48, 2334-2338. 
22.S. S. Nagarkar, B. Joarder, A. K. Chaudhari, S. Mukherjee and S. K. Ghosh, Angew Chem Int Ed, 2013, 52, 2881-2885.

23.Z. Z. Lu, R. Zhang, Y. Z. Li, Z. J. Guo and H. G. Zheng, J Am Chem Soc, 2011, 133, 4172-4174.

5 24.Z. Jin, H. Zhao, D. Yang, X. Yao and G. Zhu, Inorg Chem Commun, 2012, 25, 74-78.

25.L. Sun, H. Xing, J. Xu, Z. Liang, J. Yu and R. Xu, Dalton Trans, 2013, 42, 5508-5513.

26.Y. Takashima, V. M. Martinez, S. Furukawa, M. Kondo, S.

10 Shimomura, H. Uehara, M. Nakahama, K. Sugimoto and S. Kitagawa, Nat Commun, 2011, 2, 168.

27.O. Adeyoju, E. I. Iwuoha, M. R. Smyth and D. n. Leech, The Analyst, 1996, 121, 1885.

28.M.-L. Wang, J.-T. Wang and Y.-M. Choong, J. Food. Compos. Anal., 15 2004, 17, 187-196.

29.I. H. Boyaci, H. E. Genis, B. Guven, U. Tamer and N. Alper, J Raman Spectrosc, 2012, 43, 1171-1176.

30.L.-Y. Xin, G.-Z. Liu, X.-L. Li and L.-Y. Wang, Cryst Growth Des, 2012, 12, 147-157.

20 31.S.-Q. Zhang, F.-L. Jiang, M.-Y. Wu, J. Ma, Y. Bu and M.-C. Hong, Cryst Growth Des, 2012, 12, 1452-1463.

32.J. M. Taylor, R. K. Mah, I. L. Moudrakovski, C. I. Ratcliffe, R. Vaidhyanathan and G. K. H. Shimizu, J Am Chem Soc, 2010, 132, 14055-14057.

25 33.B. Civalleri, F. Napoli, Y. No?l, C. Roetti and R. Dovesi, CrystEngComm, 2006, 8, 364.

34.S. Bordiga, C. Lamberti, G. Ricchiardi, L. Regli, F. Bonino, A. Damin, K. P. Lillerud, M. Bjorgen and A. Zecchina, Chem Commun (Camb), 2004, 2300-2301.

30 35.P. L. Feng, J. J. Perry, S. Nikodemski, B. W. Jacobs, S. T. Meek and M. D. Allendorf, J Am Chem Soc, 2010, 132, 15487-15489. 